\title{
Effects of Recent Knowledge of Atomic Constants and of Humidity on the Calibrations of the National Bureau of Standards Thermal-Radiation Standards
}

\author{
Ralph Stair and Russell G. Johnston
}

\begin{abstract}
The National Bureau of Standards thermal-radiation standards, as established and maintained since 1913, are based primarily upon the emission of a blackbody, using the Stefan-Boltzmann constant of total radiation $\sigma=5.70 \times 10-12$ watt $/\left(\mathrm{cm}^{2} \mathrm{deg}^{4}\right)$.

The present status of this constant is reviewed in relation to the recent experimental evidence for more accurate values of the velocity of light and for the other atomic constants effecting the value of $\sigma$. It is concluded that any change in the Stefan-Boltzmann constant is unimportant at this time.

An investigation is reported on the effect of the atmospheric water vapor on the transmitted radiant intensities of these lamps at the working distance of 2 meters. The usual variations in laboratory humidities will affect the certified calibrations of these standard lamps less than 0.3 percent and hence may be neglected in all radiometric work wherein they are employed.

One section of the paper is given to general instructions for the use of these standards in precision work.
\end{abstract}

\section{Introduction}

A convenient standard of thermal radiation was early recognized as an important requirement in scientific laboratories engaged in researches involving the use of radiant energy. Toward this end such a standard was set up at the Bureau by W. W. Coblentz four decades ago $[1,2]^{1}$ This standard continues to be used for all radiometric work, not only in this country but throughout much of the scientific world.

The choice of a carbon-filament lamp for this standard was a wise one. This type of lamp was in general use for illuminating purposes in this country during the early years of the present century. No other type has been found to equal the carbon-filament lamp in ruggedness and stability, although many styles and types of lamps have been developed by industry through the years. A study was made both of lamps under carefully controlled laboratory conditions [3] and of a number of lamps returned after years of service in various laboratories. This study established that these standards retain their original calibration with no significant change for more than 200 hours if not mechanically or electrically abused. A supply of these lamps acquired by the Bureau in World War I days has been extremely useful in the preparation of standards for use in many governmental and other scientific laboratories. They are preferred to some of the more recently manufactured carbon-filament lamps.

This standard $[1,2,3]$ is based upon the radiation from a blackbody operated in the range of temperatures between about $1,000^{\circ}$ and $1,150^{\circ} \mathrm{C}$. For the original calibration it was assumed that the StefanBoltzmann constant of total radiation was $\sigma=5.70 \times$ $10^{-12}$ watt $/\left(\mathrm{cm}^{2} \mathrm{deg}^{4}\right)$. Auxiliary measurements made directly, using an absolute thermopile [2], wherein electric-energy dissipation provided the

${ }_{1}$ Figures in brackets indicate the literature references at the end of this paper. basis of the calibration showed no systematic differ ences from those with the blackbody. Other meas urements with a nocturnal-radiation instrument constructed for the United States Weather Bureau likewise showed agreement with the original blackbody calibrations.

\section{Present Status of the Radiation Constants}

The fundamental law of the blackbody, the StefanBoltzmann law, relates the total radiant flux, $W$, from a unit area of a blackbody to the absolute temperature by the relationship

$$
W=\sigma T^{4} .
$$

The precise value of the Stefan-Boltzmann constant of total radiation is based mainly upon factors associated with atomic structure according to the relationship

$$
\sigma=\frac{2 \pi^{5} c^{2} h}{15 c_{2}^{4}}
$$

where

$c=$ the velocity of light in $\mathrm{cm} / \mathrm{sec}$;

$h=$ Planck's constant of action in erg sec;

$c_{2}=$ the second radiation constant in $\mathrm{cm} \mathrm{deg} \mathrm{K}$;

$\sigma=$ the Stefan-Boltzmann constant in $\mathrm{w} /\left(\mathrm{cm}^{2} \mathrm{deg}^{4}\right.$ $\mathrm{K})$.

In the recently published least-squares summaries of fundamental constants $[4,5]$, the value given for $c$ is $2.99793 \times 10^{10} \mathrm{~cm} / \mathrm{sec}, h$ is $6.6252 \times 10^{-27} \mathrm{erg} \mathrm{sec}$, $c_{2}$ is $1.4388 \mathrm{~cm} \mathrm{deg}$, and $\sigma$ is $5.6686 \times 10^{-12} \mathrm{w} /\left(\mathrm{cm}^{2}\right.$ $\left.\operatorname{deg}^{4} \mathrm{~K}\right)$. Hence as a result of recent investigations the value of $\sigma$ is placed approximately 0.55 percent lower than that employed in $1914 .^{2}$ This difference, however, is near the level of the experimental error

Because the temperature scale in the region of $1,100^{\circ} \mathrm{C}$, that is near the values ${ }^{2}$ Because the temperature the blackbody calibrations of the original standards
of thermal radiation, requires alteration by an insignificant amount [18, 19], no correction for temperature appears to be required at this time. 
assessed in the original calibration. Because measurements with an absolute thermopile, in which only electrical constants entered, were in precise agreement with the blackbody determinations [1, 2], if any correction to the data were made at this time it probably should be based on a mean value between the two, namely, of an order of less than 0.3 percent. Taking into account the level of precision normally obtainable in radiometric work, it must be concluded that no correction to the original data is warranted at this time because of new information and changes in the value of the velocity of light or of the other atomic constants entering into radiant-energy emission.

\section{Effect of Humidity}

A knowledge of the precise radiant-energy output of these standards under conditions of variable humidity has recently been desired in a number of laboratories. Although it was pointed out by Coblentz [1] in 1914 that the radiation transmitted by the glass bulb of these lamps was confined principally to wavelengths less than 3.5 microns, and would therefore be affected but little by variations in atmospheric humidity and hence no correction for water-vapor absorption would be necessary, nev ertheless, questions have arisen from time to time regarding the magnitude of this absorption. This possibly results from the fact that a number of water-vapor absorption bands are present in the near infrared spectral region. The present investigation was undertaken, therefore, to ascertain the amount of the attenuation of the radiant flux from the NBS standards of thermal radiation to see if any correction should be applied to the data.

\subsection{Instruments and Method}

As it was known that any humidity effect upon the calibration of the NBS standards of thermal radiation must be small, as indicated above, special precautions were taken in setting up an experiment to measure precisely the radiant energy from a group of lamps as a function of atmospheric humidity in a manner little affected either by temperature changes, or air currents within the laboratory, or by stray light from the sun or other sources. Toward this end a plywood box, approximately 24 by 36 by 120 in. painted a dull black inside and fitted with a suitable arrangement of diaphragms, was set up to house the $2-\mathrm{m}$. optical path between the standard lamp and the thermopile. The box was arranged with a suitable window through which a self-recording hydrothermograph could be viewed without disturbing the humidity or temperature conditions within the box. Motor-driven fans were employed to stir the air within the box from time to time to insure relatively constant temperature and humidity conditions throughout.

Desired changes in humidity were accomplished partly by working at different seasons when different outside weather conditions existed. Thus the lowest humidities were obtained on clear, cold days during

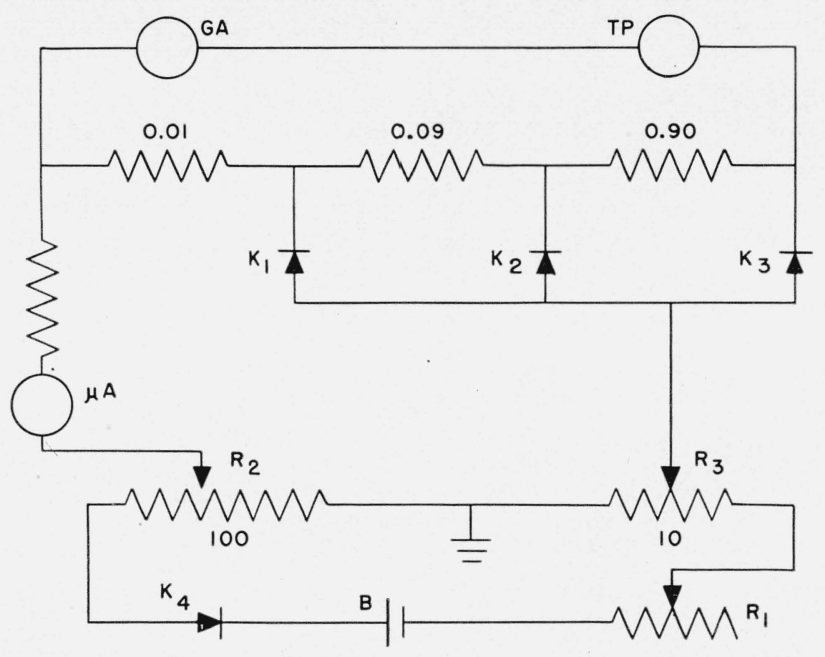

FIGURE 1. Electric circuit employed in the potentiometer for the radiant-energy measurements.

the winter, with outside air being brought into the box through a filter-trap, which was further cooled by dry ice. Additional absorption of water vapor within the box was accomplished by the use of $\mathrm{P}_{2} \mathrm{O}_{5}$ and other commercial driers. The highest humidities were obtained during the summer season by additional heating of the enclosure with electric coils and by adding live steam.

In the tests each lamp was subjected to a complete series of measurements without touching its adjustment in the socket, because it had been found that a significant error is sometimes attributable to a slight misalinement of the source relative to the thermopile.

In this work the standards were set up according to the general instructions applicable to their use. A special Lindeck type potentiometer [6] having a sensitivity of 0.005 to $0.5 \mu \mathrm{v}$ per scale division, when used with a high-grade microammeter (ranges 0 to $50 \mu \mathrm{a}$ and higher), was employed for measuring the lamp output. Thus the scale readings of microamperes corresponded directly to microvolts. This instrument, whose essential circuit elemencs are shown in figure 1, was employed in preference to the direct use of a galvanometer to avoid errors resulting from changes in circuit resistance and galvanometer sensitivity.

\subsection{Results}

Measurements were made on five lamps over a wide range in humidity. For each measurement the temperature and relative humidity were recorded. Then from the curves of figure 4, which was prepared from the Smithsonian meteorological tables [7] giving the density of water vapor at saturation as a function of temperature, the amount of precipitable water (the absolute humidity of the atmosphere) was determined in grams per cubic meter. The summer measurements on two lamps covering a humidity range of about 10 to $26 \mathrm{~g}$ of water per cubic meter are shown in figure 2 , whereas the winter 


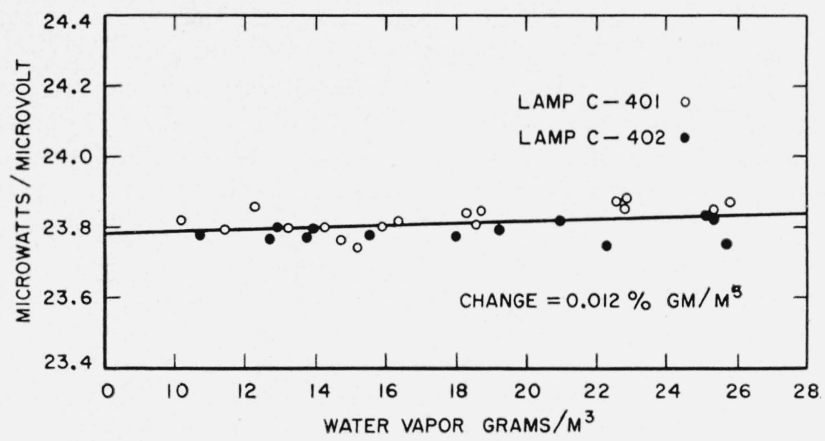

FIGURE 2. Variation of transmitted radiant energy through 2 meters as a function of humidity.

Summer measurements at high humidities, using thermopile 2028.

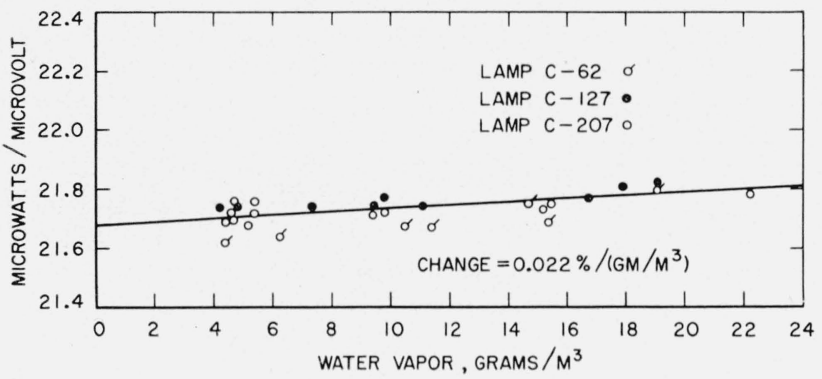

FIGURE 3. Variation of transmitted radiant energy through 2 meters as a function of humidity.

Winter measurements at low humidities, using thermopile 2650.

data on three lamps given in figure 3 cover a lower range extending from about 4 to $22 \mathrm{~g} / \mathrm{m}^{3}$. The lowest value $\left(4 \mathrm{~g} / \mathrm{m}^{3}\right)$ corresponds to the condition of the atmosphere for a room temperature near $70^{\circ}$ $\mathrm{F}$ and a relative humidity of about 20 percent. The highest value of $26 \mathrm{~g} / \mathrm{m}^{3}$ corresponds to a temperature of approximately $85^{\circ} \mathrm{F}$ and a relative humidity of about 90 percent. A value of 10 corresponds to a room temperature of $70^{\circ}$ to $75^{\circ} \mathrm{F}$ and a relative humidity of approximately 55 percent - the value normally expected in Washington during July, at which time the original blackbody calibrations were made. ${ }^{3}$ The differences in microwatts (per square centimeter) per microvolt in the two cases (see figs. 2 and 3 ) result because of the use of different thermopiles having unequal sensitivities.

An analysis by least squares, of the data for the five lamps studied, given in figures 2 and 3 , shows a mean change of 0.017 percent per gram of water per cubic meter. As the work in the original calibration of the lamp standards is thought to have been performed under conditions of a humidity of approximately $10 \mathrm{~g}$ of water per cubic meter, any correction of the original data should be made on the basis of that humidity. The data illustrated in figure 4 indicate that the range in humidities ordinarily en-

3 The distance at which the original standard lamps were calibrated, namely, $2.0 \mathrm{~m}$, was not the same as that used for the calibration of the detectors by the blackbody. The latter distance varied from about 40 to $70 \mathrm{~cm}$, and the air path was thoroughly dried by the use of $\mathrm{P}_{2} \mathrm{O}_{5}$.

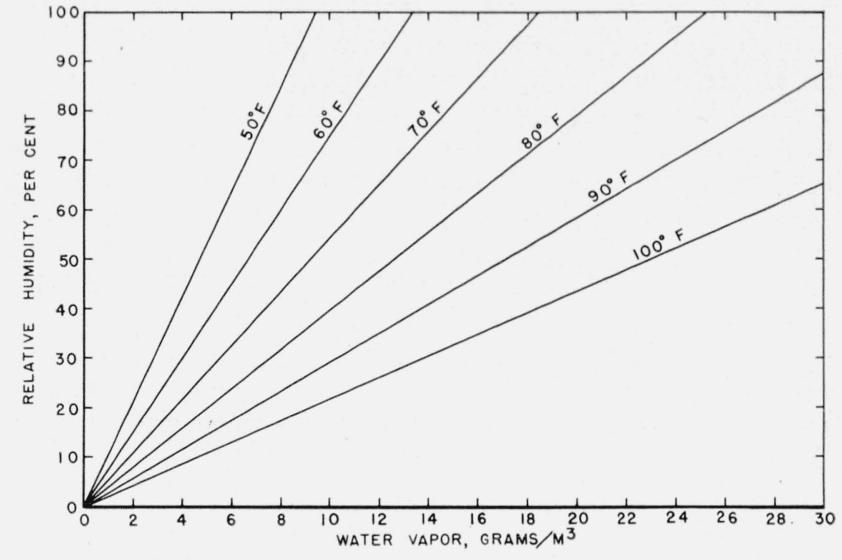

Figure 4. Total atmospheric humidity as a function of relative humidity and temperature.

From Smithsonian Meterological Tables.

countered in laboratories in this country will seldom exceed a change of more than $5 \mathrm{~g} / \mathrm{m}^{3}$ from the basic value of $10 \mathrm{~g}$ on which the original measurements were made. As a difference of $5 \mathrm{~g} / \mathrm{m}^{3}$ in humidity corresponds to a change in radiant energy of only 0.085 percent, no consideration need be taken of normal atmospheric humidities in the use of these standards in ordinary radiometric work.

A word of caution should be given at this point, however. Although no correction need be made for humidity in the use of these standards, the worker is often concerned with the measurement of radiant energy from sources rich in short ultraviolet or long infrared rays. In the former case, although water vapor may not be troublesome, transmission factors of radiometric windows require careful attention. In the infrared, especially at wavelengths longer than $4,000 \mathrm{~m} \mu$, the absorption of water vapor, $\mathrm{CO}_{2}$, and other gases $[8,11]$, as well as the transmittance of window material [12] and the spectral efficiency of radiometer detecting surfaces [13], must be taken into account.

\section{Operation of the Standards}

As noted above, the carbon-filament lamp is employed as a standard because of its proved stability [14]. Calibration and operation at voltages (and currents) below the normal rated value add much to its life and general stability. Proper handling and care, further insure its reliability.

In operations wherein a galvanometer is employed directly, extraneous currents may be kept balanced by the use of an auxiliary control current from a special battery-operated shunt arrangement [15] to improve accuracy and linearity of the response (galvanometer deflection). Where a potentiometer setup can be employed, slightly higher accuracy may be obtained. The use of a light modulator and lowimpedance tuned a-c amplifier may be found to give sufficiently accurate results and is to be highly recommended where noisy conditions prevail or where 
speed of operation is important. The potentiometer or galvanometer is to be preferred for quiet locations where accuracy or precision in results is at a premium.

The lamps employed (rated at about $50 \mathrm{w}$ ) are first seasoned, then marked for orientation (because the radiation is not the same in all directions), and then calibrated for the density of radiant flux at a fixed distance (usually $2 \mathrm{~m}$ ) in the specified direction.

In operation, the lamp is screwed into an ordinary metal socket that is held upright by some convenient support, which cannot reflect light into the radiometer. The entire lamp bulb is to be exposed to the radiometer. Sufficient time must be given (say $5 \mathrm{~min}$ ) for the glass base, which supports the filament, to become thoroughly warmed, otherwise errors will be introduced into the radiant-energy measurements The distance of the lamp is measured from the radiometer to the center (glass tip if present, the etched mark, or other special mark noted in the NBS report on a particular standard lamp) of the lamp bulb.

A black cloth, about $1 \mathrm{~m}^{2}$, should be placed about $1 \mathrm{~m}$ to the rear of the lamp. An opaque shield about 1 by $1 \mathrm{~m}$, having an opening about $10 \mathrm{~cm}$ wide and $15 \mathrm{~cm}$ high, is placed at a distance of about $25 \mathrm{~cm}$. in front of the lamp. To screen this opening, a shutter, about 20 by $20 \mathrm{~cm}$, is placed between this shield and the lamp. Facing the opening in the shield, the radiometer is placed at a distance of $2 \mathrm{~m}$ from the lamp. The shield and shutter may be made of air-separated sheets of cardboard, asbestos board, metal, or other suitable materials.

Before the lamp is lighted, the shutter should be opened and closed to determine the amount of stray thermal radiation falling upon the radiometer. This test may be applied at any time, provided the lamp has been given sufficient time to come to room temperature. The wall and screen to the rear of the lamp may be cooler than the shutter, which will cause a negative deflection. The correction to the observed lamp deflection is, in that case, positive. It is desirable to make the calibration in a dimly lighted room to avoid errors from sunlight that is continually varying with cloudiness, thus varying stray radiant energy within the room as well as the temperature of the walls, and also causing air currents near the radiometer.

The measurement of the current through the lamp is, of course, sufficient to determine the radiant flux, the voltage being useful mainly to determine whether the lamp has remained constant.

To conserve the calibration, which gradually changes with use, these lamps should be kept as reference standards only, and other lamps used as working standards in all cases where extensive radiometric comparisons are made.

These instructions and standards of radiation apply to radiometers used in air. If a window is used on the radiometer, for example, as in a vacuum radiometer, then a correction has to be made for the radiant flux absorbed by the window [16, 17], for the particular lamp used as a standard, and for the source measured. This absorption is a function of the temperature of the lamp filament. For example, it was found that for a glass or quartz window about $1.5 \mathrm{~mm}$ in thickness, the transmission amounted to about 83 percent when a certain standard lamp was operated on $0.35 \mathrm{amp}$, and increased to 84 percent when the lamp was operated on 0.40 amp. Using a fluorite $\left(\mathrm{CaF}_{2}\right)$ window, the transmission is higher (about 91.5 percent) and varies somewhat less with the current ordinarily used in the lamp. For example, using a certain standard lamp, the transmission through a fluorite window varied from 91.0 percent on $0.25 \mathrm{amp}$ to 92 percent on $0.4 \mathrm{amp}$, with an average value of 91.6 percent on $0.35 \mathrm{amp}$.

The transmission of the window varies also with the spectral quality of the radiant flux emitted by the source under investigation. This must also be taken into consideration.

The thermal-radiation sensitivity of a surface thermopile varies with the degree of evacuation; when highly evacuated this sensitivity may be several times as great as in air. Because at low air pressures the sensitivity is variable with the pressure, great care must be taken to test the sensitivity of the thermopile under the exact conditions existing during its use.

The identical area of the radiometer receiver should be exposed to the standard of radiation as is used in the measurements of the unknown source.

\section{Example of a Thermopile Calibration}

The thermopile was exposed, at $2 \mathrm{~m}$, to the standard of radiation that was operated on $0.350 \mathrm{amp}$, under which conditions the radiant flux was $84.9 \times$ $10^{-6} \mathrm{w} / \mathrm{cm}^{2}$ or $20.3 \times 10^{-6} \mathrm{~g}$ cal $/ \mathrm{cm}^{2} / \mathrm{sec}$. As the thermopile was covered with a fluorite window, only 91.6 percent was transmitted, or $0.916 \times 84.9 \times 10^{-6}=$ $77.8 \times 10^{-6} \mathrm{w} / \mathrm{cm}^{2}$. Under these conditions, the galvanometer gave a scale deflection of $3.15 \mathrm{~cm}$. Hence, a deflection of $1 \mathrm{~cm}$ indicated that $77.8 \times$ $10^{-6} \div 3.15=24.7 \times 10^{-6} \mathrm{w} / \mathrm{cm}^{2}$ was incident on the thermopile element.

Suppose that the radiant flux of a source rich in infrared rays is being measured, in which the fluorite window transmits only 80 percent of the total. Under this condition, a deflection of $1 \mathrm{~cm}$ indicated $24.7 \times 10^{-6} \div 0.80=30.9 \times 10^{-6} \mathrm{w} / \mathrm{cm}^{2}$ was incident on the thermopile window.

If the radiometer window is of quartz, then the spectral correction for losses by reflection is about 8.5 percent for all wavelengths from the ultraviolet to $2 \mu$ in the infrared, where absorption begins.

Owing to the large heat capacity of the filament there is no appreciable difference in the radiation emitted by this type of lamp on 60-cps a-c and on $\mathrm{d}-\mathrm{c}$ generators. The use of lower frequencies is questionable. In order to maintain a constant voltage it is preferable to use a storage battery. However, by the use of a small-voltage regulator and a small-variable-voltage transformer, satisfactory voltage and current control may be obtained on standard $110 \mathrm{v}, 60-\mathrm{cps}$ circuits. 


\section{References}

[1] W. W. Coblentz, Measurements on standards of radiation in absolute value, Bul. BS 11, 98 (1914) S227.

[2] W. W. Coblentz and W. B. Emerson, Studies of instruments for measuring radiant energy in absolute value: An absolute thermopile, Bul. BS 12, 503 (1916) S261.

[3] W. W. Coblentz and R. Stair, The present status of the standards of thermal radiation maintained by the Bureau of Standards, BS J. Research 11, 79 (1933) RP578.

[4] J. A. Bearden, M. D. Earle, J. M. Minkowski, and J. S. Thomsen, Present status of the atomic constants, Phys. Rev. 93, 629 (1954).

[5] J. W. M. DuMond and E. R. Cohen, Least squares adjustment of the atomic constants, 1952, Rev. Mod. Phys. 25, 691 (1953).

[6] Forrest K. Harris, Electrical measurements (John Wiley \& Sons, Inc., New York, N. Y., 1952).

[7] Robert L. List, Smithsonian meteorological tables, 6th ed., table 108, p. 382 (1951).

[8] W. W. Coblentz, Radiometric investigation of water of crystallization, light filters, and standard absorption bands, Bul. BS $\boldsymbol{\gamma}, 619$ (1911) S168.

[9] A. Adel, Atmospheric absorption of infrared solar radiation, Astrophys. J., 89, 1 (1939); 91, 1 (1940); 94, 375, 379 , and 451 (1941).

[10] W. S. Benedict and Earle K. Plyler, Absorption spectra of water vapor and carbon dioxide in the region of 2.7 microns, J. Research NBS 46, 246 (1951) RP2194.
[11] W. S. Benedict, H. H. Claassen, and J. H. Shaw, Absorption spectrum of water vapor between 4.5 and 13 microns, J. Research NBS 49, 91 (1952) RP2347.

[12] Nora M. Mohler and John R. Loofbourow, Optical filters, Am. J. Phys. 20, 499 and 579 (1952).

[13] Earle K. Plyler and Joseph J. Ball, Infrared absorption of deposited blacks, J. Opt. Soc. Am. 38, 988 (1948).

[14] E. B. Rosa and G. W. Middlekauff, Carbon filament lamps as photometric standards, Proc. Am. Inst. Elec. Engrs. 29, 1191 (1910).

[15] W. W. Coblentz, R. Stair, and J. M. Hogue, A balanced thermocouple and filter method of ultraviolet radiometry, with practical applications, BS J. Research $\mathbf{7}, 723$ (1931) RP370.

[16] W. W. Coblentz, Absorption, reflection and dispersion constants of quartz, Bul. BS 11, 471 (1913) S237.

[17] W. W. Coblentz, Infrared transmission and refraction data on standard lens and prism material, BS Sci. Pap. 16, 701 (1920) S401.

[18] H. F. Stimson, The International Temperature Scale of 1948, J. Research NBS 42, 209 (1949) RP1952.

[19] Robert J. Corruccini, Differences between the International Temperature Scales of 1948 and 1927, J. Research NBS 43, 133 (1949) RP2014.

Washington, June 10, 1954. 